\title{
Intracranial tuberculoma in motor cortex: a central cause of isolated unilateral foot drop
}

\author{
Akhila Kumar Panda
}

Department of Neurology, Institute of Human Behaviour \& Allied Sciences (IHBAS), Delhi, India

\section{Correspondence to} Dr Akhila Kumar Panda, drakhilapanda@gmail.com
To cite: Panda AK. BMJ Case Rep Published online: [please include Day Month Year] doi:10.1136/bcr-2013010285

\section{DESCRIPTION}

A 9-year-old girl presented with one episode of focal short lasting nocturnal seizure without impaired consciousness involving right lower limb that persisted for $1 \mathrm{~min}$. This event was neglected by the patient and brought attention on retrospective analysis. There was no history of fever, headache, vomiting, visual blurring or altered sensorium. Twenty days later, she developed foot drop in her right leg which led to problems with walking. There was no history of trauma, hypopigmented patch, sensory loss or radicular pain. Cranial nerve examinations were normal including fundi. Tone was normal in all limbs except in her right ankle which was hypotonic, and the power of right ankle dorsiflexion was $2 / 5$, plantar flexion was $4 / 5$ and intrinsic muscles of foot were $1 / 5$. Power around hip and knees were 5/5. Upper limbs and left lower limb were spared. The right knee and ankle jerks were pathologically brisk with right ankle clonus. She had a high steppage slapping gait with right foot drop. Laboratory investigations were unremarkable except for raised erythrocyte sedimentation rate $(42 \mathrm{~mm}$ in first hour). Nerve conduction test, needle electromyography and whole spine MRI were unremarkable. MRI (3 Tesla) of brain with axial sequences showed T2 hyperintense, T1 hypointense and diffusion restricted granulomatous lesion with perilesional oedema in the left precentral gyrus (motor cortex) (figures 1-3). Sagittal and coronal section of $\mathrm{T} 1$ gadolinium contrast sequences

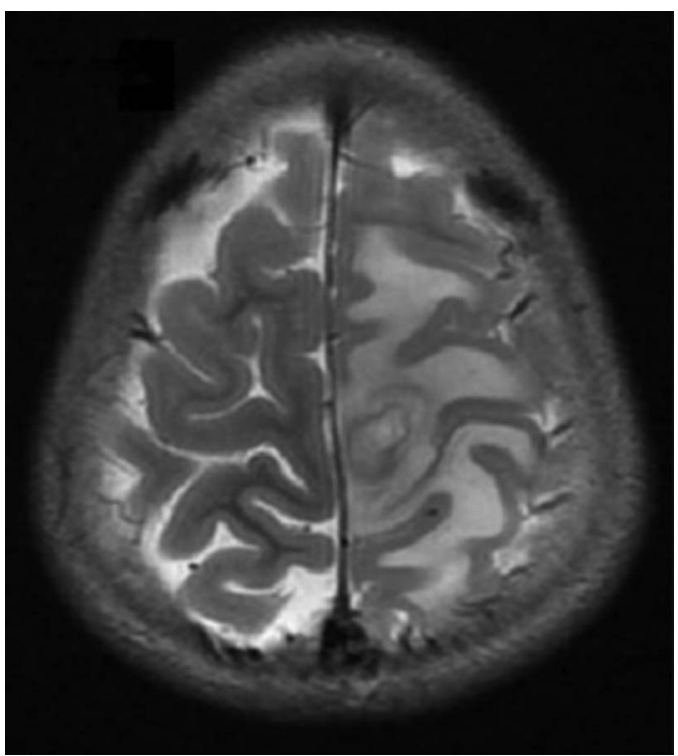

Figure 1 MRI (3 Tesla) of brain with axial sequences showed T2 hyperintense granulomatous lesion with perilesional oedema in left precentral gyrus.

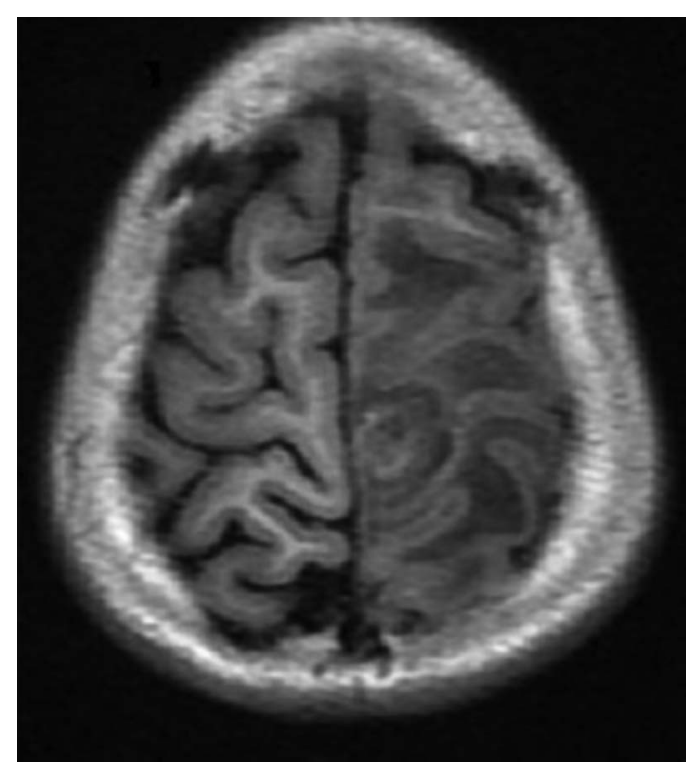

Figure 2 MRI (3 Tesla) of brain with axial sequence showed T1 hypointense granulomatous lesion with perilesional oedema in left precentral gyrus.

of above lesion revealed a well-circumscribed thickwalled saggy ring enhanced granulomatous lesion (tuberculoma) (figures 4 and 5). There was no other evidence of systemic tuberculosis.

Among the cerebral causes of foot drop, parasagittal meningioma, neuroschistosomiasis, high-grade

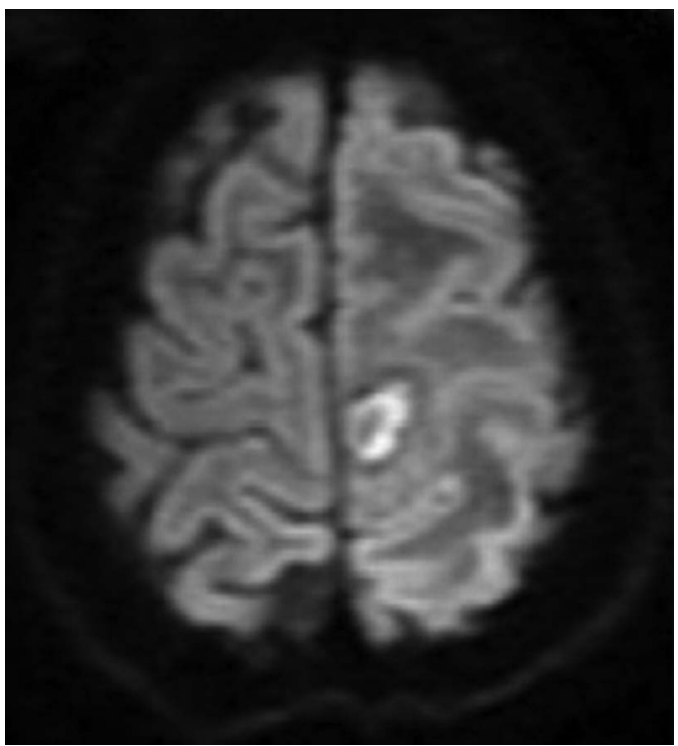

Figure 3 Diffusion weighted image showed a hyperintense (restricted diffusion) lesion in the left motor cortex. 


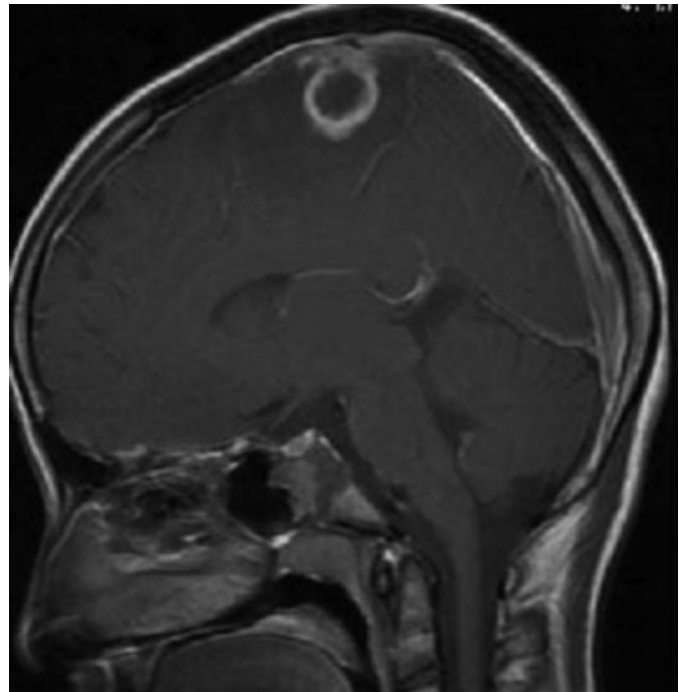

Figure 4 Sagittal section of T1 gadolinium contrast MRI of brain revealed a well-circumscribed thick-walled saggy ring enhanced granulomatous lesion (tuberculoma) present in left precentral gyrus (motor cortex).

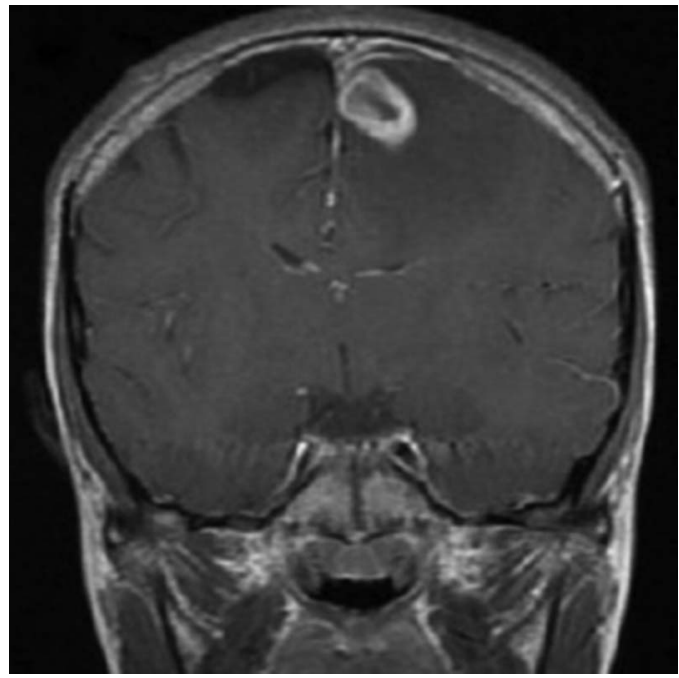

Figure 5 Coronal section of T1 gadolinium contrast MRI of brain revealed a well-circumscribed thick-walled saggy ring enhanced granulomatous lesion (tuberculoma) present in left precentral gyrus (motor cortex). glioma, granulomatous lesion including tuberculoma involving motor cortex has been described in literatures. ${ }^{1-3}$ This case needs to be considered as a rare presentation of relatively common central nervous system infections.

\section{Learning points}

- Although the most common cause of foot drop is peripheral nervous system disorder, rare central nervous system lesions should always be considered.

- Detail structured clinical interview and comprehensive neurological examination may disclose the true aetiology.

- Upper motor neuron signs in a case of isolated foot drop points towards central cause.

Competing interests None.

Patient consent Obtained.

Provenance and peer review Not commissioned; externally peer reviewed.

\section{REFERENCES}

1 Wilbers J, dema A, Gijtenbeek A. A bilateral foot drop due to neuroschistosomiasis. J Neurol 2010;257:853-5

2 Lath R, Rajshekhar V. Unilateral foot drop. Postgrad Med J 1996;72:573-4.

3 Goia E, Hamilton L, Chan J, et al. Unilateral foot drop as an initial presentation of a brain tumor in a child. J Child Neurol. Published Online First: 1 Mar 2013. doi:10.1177/0883073813479172

Copyright 2013 BMJ Publishing Group. All rights reserved. For permission to reuse any of this content visit http://group.bmi.com/group/rights-licensing/permissions.

BMJ Case Report Fellows may re-use this article for personal use and teaching without any further permission.

Become a Fellow of BMJ Case Reports today and you can:

- Submit as many cases as you like

- Enjoy fast sympathetic peer review and rapid publication of accepted articles

- Access all the published articles

- Re-use any of the published material for personal use and teaching without further permission

For information on Institutional Fellowships contact consortiasales@bmjgroup.com

Visit casereports.bmj.com for more articles like this and to become a Fellow 